\title{
Extraperitoneal uterosacral ligament suspension by using the cervix as a traction device
}

\author{
Manidip Pal ${ }^{1}$. Soma Bandyopadhyay ${ }^{2,3}$ \\ Received: 4 June 2019 / Accepted: 8 October 2019 / Published online: 7 February 2020 \\ (C) The International Urogynecological Association 2020
}

\begin{abstract}
The present video demonstrates extraperitoneal uterosacral ligament suspension (ULS) while performing vaginal hysterectomy for POP-Q stage 3 prolapse. The ULS bites were taken before severing the uterosacral ligament using the cervix as a traction device. Two ULS sutures were applied on each side to the distal half of the intermediate part. Superior 1st ULS suture with permanent material (polypropylene) was applied to the uppermost exposed area. Inferior 2nd ULS suture with delayed absorbable material (polyglactin) was $0.5-1 \mathrm{~cm}$ distal to the superior suture. Next, the usual first clamp of the vaginal hysterectomy (VH) on a cardinal-uterosacral ligament was applied about $1 \mathrm{~cm}$ below the second ULS suture. The VH was completed. The ULS sutures were anchored to the vault via either the vesico-vaginal septum or the recto-vaginal septum. Permanent sutures were not brought outside the vaginal epithelium. In 51 cases there was no urological injury. On follow-up (average 2.3 years), 8.3\% cases had stage 1 POP, $91.6 \%$ had no POP.
\end{abstract}

Repetition is not done as the detailed technique is described in Pal and Bandyopadhyay [1].

Authors' contributions M.P.: project development, data collection, manuscript writing and editing; S.B.: project development, manuscript writing and editing.

\section{Compliance with ethical standards}

Financial disclaimer/conflicts of interest The authors declare that they have no conflicts of interest.

Electronic supplementary material The online version of this article (https://doi.org/10.1007/s00192-019-04147-w) contains supplementary material. This video is also available to watch on http://link.springer. $\mathrm{com} /$. Please search for this article by the article title or DOI number, and on the article page click on 'Supplementary Material'

Soma Bandyopadhyay

somapb@gmail.com

1 Department of Obstetrics \& Gynaecology, College of Medicine \& JNM Hospital, WBUHS, Kalyani, Nadia, West Bengal, India

2 Department of Obstetrics \& Gynaecology, Katihar Medical College, Katihar, Bihar, India

3 Tolly Twin, Block C, 2nd Floor, B-1, Kabardanga More, 327, M.G. Road, Kolkata 700104, India
Consent Written informed consent was obtained from the patient for publication of this case report and any accompanying images.

\section{Reference}

1. Pal M, Bandyopadhyay S. Modified extraperitoneal uterosacral ligament suspension for prevention of vault prolapse after vaginal hysterectomy. Int J Urogynecol. 2019;30(4):633-7.

Publisher's note Springer Nature remains neutral with regard to jurisdictional claims in published maps and institutional affiliations. 